sentations to the relevant departments, as other professional bodies do, an unimpressive comment on this suggestion.

\section{NUCLEAR POWER}

\section{Fuel Company Announced}

BRITAIN's nuclear fuel business is to be handled by a new government controlled company, British Nuclear Fuels Ltd, according to a bill put forward by the Minister of Technology, Mr Anthony Wedgwood Benn, published last week (Atomic Energy Authority Bill, HMSO, 3s). The AEA's smaller but buoyant radio-isotopes business will also be established as a separate company, to be known as The Radiochemical Centre Ltd.

The setting up of British Nuclear Fuels is the second stage of the reorganization of the nuclear industry that was begun by $\mathrm{Mr}$ Benn in 1968 and represents the next step in switching from a researchoriented to a market-oriented industry. The third stage of the reorganization was outlined in the green paper, published in January this year, which envisaged the merger of the research side of the AEA with other research establishments of the Ministry of Technology to form a new British Research and Development Corporation.

Five establishments of the AEA will be transferred to British Nuclear Fuels if the new bill is passed. These are at Capenhurst in Cheshire, Calder Hall in Cumberland, Chapelcross in Dumfriesshire, Springfields in Lancashire and Windscale in Cumberland. Radiochemical Centre will be comprised of the radiochemical centre at Amersham in Buckinghamshire and a contingent from the Atomic Energy Research Establishment at Harwell. BNF will become the British component in the joint scheme negotiated by the governments of the Netherlands, Britain and West Germany for the production of enriched uranium by the gas centrifuge process, and will assume a minority shareholding in the two reactor consortia, TNPG and BNDC.

There is not expected to be much opposition to the setting up of the fuel companies. The present British market for nuclear fuels is estimated at £25 million, and is expected to rise to $£ 100$ million by 1980 . The world market is likely to have exceeded $£ 1,000$ million by 1980 , and the need for a strong commercially oriented body to manage this expanding business is widely recognized. Nuclear fuel is, of course, the most lucrative side of the nuclear power business. Sales of radio-isotopes are also growing, with half the radiochemical centre's $£ 4$ million trade coming from overseas.

The exact composition of the $\mathrm{BNF}$ shareholding is not yet known, but companies believed to be interested in participating include Imperial Chemical Industries, Rolls-Royce and Rio Tinto Zinc. Mr Benn is known to be in favour of cooperation between government and private industry in this sort of venture, a view which may, however, be challenged by the opposition spokesman on trade and technology, Sir Keith Joseph, when the bill is debated in the House of Commons. The bill was introduced in the House of Lords last week, but even the most optimistic estimates make it unlikely that either of the companies will start operating before October.

\section{DRUGS}

\section{Hard and Soft Distinguished}

STIFFER penalties for drug "pushers" and stringent provisions to prevent doctors prescribing "irrespon. sibly" are the main features of the Home Sccretary's comprehensive new drugs bill. Controlled drugs are divided, according to their harmfulness, into three groups so that for the first time "hard" and "soft" drugs such as heroin and cannabis are treated differently (The Misuse of Drugs Bill, HMSO, 5s).

The bill assigns different penalties for misuse in each of the three controlled groups. The group considered most dangerous includes heroin, morphine, cocaine and LSD, and the penalties for producing or supplying these "Class A" drugs are up to fourteen years imprisonment and an unlimited fine. The penalty of seven years for being in possession of these substances is less than the present maximum sentence of ten years for drugs included under the Dangerous Drugs Act, 1967, a concession which reflects the present practice in the courts of imposing lighter sentences on drug users than on drug pushers.

Amphetamines, cannabis and codeine are bracketed together as "Class B" drugs. Maximum penalties for pushing these drugs are still fourteen years imprisonment and a fine, but the penalty for illegal possession is down to five years. Sentences for possession of the least harmful group of drugs ("Class C"), which includes some of the less dangerous stimulants, are up to two years imprisonment and a fine. Barbiturates are not specifically carried by the new bill but their position is under review.

A new power proposed in the bill is that of adding new drugs to the controlled list as soon as it seems that they may become dangerous. The danger would be assessed by an advisory committce and a panel of experts, but the formal procedures involved in getting a drug classified could take place quite quickly, within a few weeks if necessary. The present system of putting new drugs on the list requires international agreement and can take up to two years.

Another new provision in the bill concerns information on the supply of drugs. In regions where the misuse of drugs is causing "social problems", the Home Secretary can ask doctors or pharmacists for details of the quantity of drugs and the number of prescriptions they have supplied.

\section{SATELLITE \\ SRC Advertises its Vacancy}

THE Science Research Council has strange ways of announcing its achievements. Advertisements in the daily press last week (Daily Telegraph, March 13) for a satellite engineer to work on a new satellite in the Ariel series concerned with cosmic $\mathrm{X}$-rays have revealed that at least project definition and feasibility studies are complete for the most attractive British satellite payload yet attempted. This is part of the longstanding US-UK cooperative programme (drawn up in 1959) according to which NASA provides the launch and Britain the scientific ideas and hardware. So far three satellites have been launched and one 